\title{
Model simulations of the ecological dynamics induced by climate and nutrient load changes for deep subalpine Lake Maggiore (Italy/Switzerland)
}

\author{
Andrea Fenocchi, ${ }^{1 *}$ Michela Rogora, ${ }^{2}$ Aldo Marchetto, ${ }^{2}$ Stefano Sibilla,,${ }^{1}$ Claudia Dresti ${ }^{2}$ \\ ${ }^{1}$ Department of Civil Engineering and Architecture, University of Pavia, Via Ferrata 3, 27100 Pavia; ${ }^{2} \mathrm{CNR}-$ Water Research Institute, \\ Largo Tonolli 50, 28922 Verbania Pallanza, Italy
}

\begin{abstract}
Climate warming affects lake ecosystems both through its direct effect on the phenology of species and through the alteration of the physical and chemical environments, which in turn affects community composition. In deep lakes, stratification enhancement and mixing reduction have already been observed, leading to hypolimnetic anoxia and to the rise of cyanophytes. The increase in stability depends on the rise of air temperature due to global emissions of greenhouse gases (GHG). Primary production could then either increase with rising epilimnetic temperature and buoyancy or decrease as fewer nutrients are upwelled from deep layers. The prevailing outcome, as well as the quantitative and temporal dynamics of all climate-induced modifications, depend on the specific lake characteristics. Individual analyses are then needed, one-dimensional coupled hydrodynamic-ecological numerical models being suitable tools for such predictions. Here, we simulated with GLM-AED2 (General Lake Model - Aquatic EcoDynamics) the 2020-2085 dynamics of the oligomictic and oligotrophic deep subalpine Lake Maggiore (Italy/Switzerland), according to the Swiss Climate Change Scenarios $\mathrm{CH} 2011$. Multiple realisations were performed for each scenario with random meteorological series obtained from the Vector-Autoregressive Weather Generator (VG), highlighting the uncertainties related to meteorology. Increase and decrease of nutrient loads were also tested. Results show that anoxia would occur in the hypolimnion regardless of nutrient input reduction, unless global GHG emissions were immediately reduced. Total phytoplankton biomass would be weakly affected by climate change, strongly depending on nutrient input, yet water warming would cause cyanophytes to compete with diatoms. Therefore, the fate of Lake Maggiore would be tied to both global and local environmental policies.
\end{abstract}

\section{INTRODUCTION}

Climate warming has been affecting lake ecosystems during the last decades and its impact is projected to increase in the future (Adrian et al., 2009; Carpenter et al., 2011). Organisms not only suffer from the direct effects of rising water temperature, which alter their phenology (Scheffer et al., 2001; Elliott et al., 2005; Peeters et al., 2007), but also endure the larger influence of physical and chemical processes altered by climate

Corresponding author: andrea.fenocchi@unipv.it

Key words: Water warming; stability increase; hypolimnetic hypoxia/anoxia; future ecosystem dynamics; cyanophyte dominance; 1D coupled hydrodynamic-ecological model.

Edited by: Diego Fontaneto, CNR-Water Research Institute, Verbania Pallanza, Italy.

Received: 4 February 2020

Accepted: 3 June 2020.

This work is licensed under a Creative Commons Attribution NonCommercial 4.0 License (CC BY-NC 4.0).

${ }^{\circ}$ Copyright: the Author(s), 2020

Licensee PAGEPress, Italy

J. Limnol., 2020; 79(3): 221-237

DOI: 10.4081/jlimnol.2020.1963 warming (Anderson, 2000; Jankowski et al., 2006; Matzinger et al., 2007). This especially holds for deep holomictic lakes, where climate warming strengthens stability by intensifying the vertical temperature gradient between surface and bottom waters (Livingstone, 2003). The consequent reduction of mixing, especially in the frequency and intensity of full turnovers (Fenocchi et al., 2018), causes: i) nutrient accumulation and oxygen depletion in the hypolimnion (Rogora et al., 2018); ii) diminution of surface nutrient availability at the end of winter, due to reduced upwelling (Yankova et al., 2017). Hypolimnetic anoxia would cause the release of nutrients and toxic substances from sediments and the disappearance of species living in deep waters, while decreased epilimnetic fertilisation would propagate in the ecosystem and lead to the reduction of fish stock (Carpenter et al., 1998; Jankowski et al., 2006; Matzinger et al., 2007; Yankova et al., 2017; Rogora et al., 2018). Oligomictic basins would be seriously at risk of turning meromictic through the disappearance of chance complete-mixing events, which are vital for deep-water oxygen replenishment (Matzinger et al., 2007; Sahoo et al., 2013). More intense phytoplankton blooms could occur: i) in spring, also arising earlier due to higher temperatures (Elliott et al., 2005; Peeters et al., 2007; Schlabing et al., 2014); ii) in summer, as increased diffuse inputs due to rising high-intensity short-duration rainfalls would support blooms of cyanophytes (Callieri et al., 2014; Morabito et al., 2018). Cyanophytes are generally 
expected to dominate at the expense of diatoms and chlorophytes, both because of their higher temperature optimum and following the increase of stability, which favours buoyant species over sinking ones for light competition (Jöhnk et al., 2008; Posch et al., 2012; Visser et al., 2016; Yankova et al., 2017).

The mentioned outcomes of climate warming would hamper the efforts against eutrophication, preventing recovery and increasing the required interventions (Jankowski et al., 2006; Matzinger et al., 2007; Moss et al., 2011; Posch et al., 2012; Winder, 2012). Many studies hence suggest that a mitigating measure for climate warming might be further reduction of nutrient loads. This solution would generally work for shallow lakes (Trolle et al., 2008a, 2008b, 2011), in which import and export of nutrients prevail due to the small water residence times (Pinardi et al., 2015; Fenocchi and Sibilla, 2016), but would be far more uncertain for deep lakes, in which nutrient recycling driven by mixing and stratification prevails. For these latter basins, the increase of stability and the rising hypolimnion isolation cannot be managed in most cases by local strategies aimed at reducing external loads (Matzinger et al., 2007). Restraint of global warming through the decrease of the global emissions of greenhouse gases (GHG) would rather be required. The quantitative and temporal response of deep lakes to climate change at the physical, chemical and ecological levels depends on the specific morphometry, water chemistry, community composition and history of the basin (Rempfer et al., 2010). Total phytoplankton biomass could either increase with rising temperature and buoyancy or decrease due to reduced nutrient replenishment from deep waters (Jöhnk et al., 2008). The hypolimnion could become permanently anoxic, with the oxic layer gradually thinning, or merely experience moderate hypoxia at the end of summer, depending on mixing reduction and oxygen consumption (Jankowski et al., 2006; Schwefel et al., 2016). Specific long-term prediction studies would then be needed to plan possible countermeasures to climate change and to warn against issues such as toxic algal blooms (Trolle et al., 2014) and fish disappearance (Yankova et al., 2017).

One-dimensional (1D) coupled hydrodynamicecological numerical models are suitable tools to perform these long-term studies on deep lakes, their horizontally averaged output being meaningful for predictions over extended periods (Hamilton and Schladow, 1997). They can account for the interplay among the physical, chemical and biological levels of basins (Hamilton and Schladow, 1997; Bruce et al., 2006), without the need for spatially distributed boundary conditions and with much smaller computational efforts than three-dimensional (3D) models. Coupled hydrodynamic-ecological models yet strongly rely on calibration, as biological processes are intensively parameterised (Hamilton and Schladow, 1997; Trolle et al., 2011, 2014, 2015). This hinders future projections, as phenomena such as immigration of new phytoplankton species and adaptation of existing ones cannot be reproduced (Mieleitner and Reichert, 2006; Özkundakci et al., 2011; Trolle et al., 2011, 2014, 2015; Fenocchi et al., 2019). Parameterisation of upper ecosystem levels also does not allow reflecting top-down effects on lower modelled levels (Jeppesen et al., 2005; Cui et al., 2016). Nevertheless, 1D coupled hydrodynamic-ecological models would give insightful qualitative answers for studies on conditions beyond the observed ones, given that results are critically framed (Gal et al., 2009, 2014; Özkundakci et al., 2011; Fenocchi et al., 2019).

This study aims at determining through the 1D coupled hydrodynamic-ecological model GLM-AED2 (General Lake Model - Aquatic EcoDynamics; Hipsey et al., 2013, 2014) the 2020-2085 dynamics of the main chemical parameters and phytoplankton groups for Lake Maggiore (Italy/Switzerland), a deep oligomictic and oligotrophic subalpine lake. Its hypolimnion has always been well-oxygenated, though a significant decrease of dissolved oxygen has been observed over the last few years (Rogora et al., 2018). The thermal dynamics of the lake in the $21^{\text {st }}$ century were predicted with a pure hydrodynamic model in Fenocchi et al. (2018), while the coupled hydrodynamic-ecological model was calibrated in Fenocchi et al. (2019). The air temperature increase forecasts for the area by the Swiss Climate Change Scenarios CH2011 (CH2011, 2011; Fischer et al., 2015) were considered, spanning from the mildest to the most impacting scenarios. Effects of changes in nutrient loads were also evaluated, considering time-invariant input and linear variation of loads up to $\pm 30 \%$ in 2085 for each climate scenario. As chance full turnovers are fundamental in shaping the vertical thermal and chemical structure of Lake Maggiore, we simulated the complete 2020-2085 period and performed 200 realisations for each scenario using random meteorological data series produced by the Vector-Autoregressive Weather Generator (VG; Schlabing et al., 2014). Results were statistically analysed over the realisations, highlighting the uncertainties over meteorology.

\section{METHODS}

\section{Case study}

Lake Maggiore is a deep fluvio-glacial lake at the southern border of the Central Alps. Its surface mostly lies is Italy $(80 \%)$, the remnant northern area being in Switzerland (Fig. 1). It has a surface area of $213.0 \mathrm{~km}^{2}$, a volume of $38.1 \mathrm{~km}^{3}$ and a maximum depth of $370.0 \mathrm{~m}$ at 
the Ghiffa site (Fig. 1) for the reference lake elevation $193.5 \mathrm{~m}$ asl. Lake Maggiore drains the $6599 \mathrm{~km}^{2}$-wide upstream watershed of River Ticino, its only outflow, which includes the surrounding Lake Lugano, Lake Orta and Lake Varese. It has 12 main inflows, the largest ones being River Ticino and River Toce (Fig. 1). Lake level and outflowing discharge are regulated by the Miorina Dam (Fig. 1). The theoretical water residence time of Lake Maggiore is 4.2 years.

The physical, chemical and ecological characters of Lake Maggiore have been monitored since the 1950s by the Water Research Institute of the Italian National
Research Council (CNR-IRSA) in Verbania Pallanza, since 1981 within the framework of the International Commission for the Protection of Italian-Swiss Waters (CIPAIS). Lake Maggiore is oligomictic and a decrease in the frequency of full turnover and in the winter mixing depth in years without complete mixing has been observed in the last decades, owing to the increase in stability brought about by climate warming (Ambrosetti and Barbanti, 1999; Rogora et al., 2018). This trend would persist for the rest of the $21^{\text {st }}$ century, leading to enduring stratification unless global GHG emissions were reduced within the next few years (Fenocchi et al., 2018).

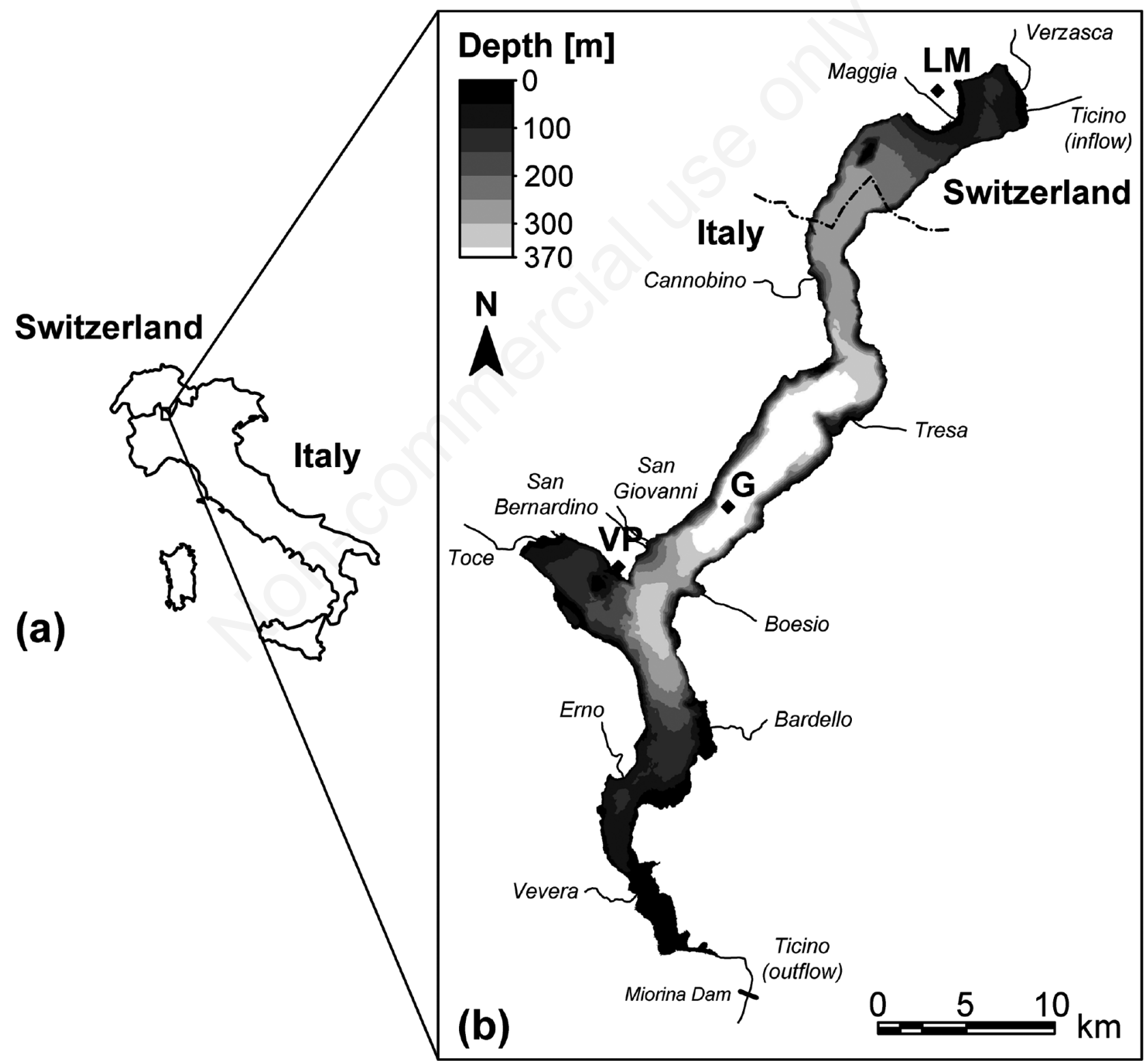

Fig. 1. Position (a) and map (b) of Lake Maggiore, displaying the bathymetry, the final reaches of the 12 main inflows and the considered data stations. VP, Verbania Pallanza weather station; LM, Locarno-Monti weather station; G, Ghiffa sampling site. 
As a result, dissolved oxygen concentration in the $200-$ $370 \mathrm{~m}$ deep hypolimnion of Lake Maggiore has been decreasing since 2006, when the last full turnover occurred, presently approaching $5 \mathrm{mg} \mathrm{L}^{-1}$ (Rogora et al., 2018). An increase of hypolimnetic phosphorus has been concurrently observed (Rogora et al. 2018). The lake is currently oligotrophic, P-limited and diatom-dominated (Morabito et al., 2012), having recovered from the 1980s till the 2000s from the trophic deterioration of the 1960s and 1970s (Salmaso et al., 2014). Deep-water dissolved oxygen concentrations at the trophic peak were nevertheless not as low as in the present (Rogora et al., 2018). Climate change has already triggered relevant ecological effects in Lake Maggiore (Salmaso et al., 2014), such as shifts in phytoplankton species and the occurrence of summer blooms of chlorophytes (Tapolczai et al., 2015; Stefani et al., 2016; Morabito et al., 2018) and cyanophytes (Callieri et al., 2014; Stefani et al., 2016; Morabito et al., 2018).

\section{Field data}

Water temperatures and concentrations of chemical variables (dissolved oxygen $\mathrm{O}_{2}$, orthophosphate $\mathrm{PO}_{4}$, nitrate $\mathrm{NO}_{3}$, ammonium $\mathrm{NH}_{4}$, silica $\mathrm{SiO}_{2}$, dissolved and particulate organic phosphorus DOP and POP, dissolved and particulate organic nitrogen DON and PON, dissolved inorganic and organic carbon DIC and DOC, particulate organic carbon POC) sampled at depths $0 \mathrm{~m}, 5 \mathrm{~m}, 10 \mathrm{~m}$, $20 \mathrm{~m}, 30 \mathrm{~m}, 50 \mathrm{~m}, 100 \mathrm{~m}, 150 \mathrm{~m}, 200 \mathrm{~m}, 250 \mathrm{~m}, 300 \mathrm{~m}$, $360 \mathrm{~m}$ at the Ghiffa site (Fig. 1) on 11 January 2016 were set as initial conditions for the simulations. The biovolumes of the modelled phytoplankton groups measured from a $0-20 \mathrm{~m}$ integrated sample taken in the same site on the same day also served as initial conditions, converted into the carbon concentrations needed by AED2 according to Reynolds (2006).

The mean monthly discharges and the concentrations of chemical variables $\left(\mathrm{O}_{2}, \mathrm{PO}_{4}, \mathrm{NO}_{3}, \mathrm{NH}_{4}, \mathrm{SiO}_{2}, \mathrm{DOP}\right.$, DON, DIC, DOC) sampled with monthly frequency at the mouths of the 12 main tributaries of Lake Maggiore (Fig. 1) from 21 November 2005 to 18 January 2016 were employed to estimate the input loads to the basin.

The 1998-2015 daily series of air temperature, shortwave radiation, relative humidity and wind speed measured by the Verbania Pallanza weather station (Fig. 1) were used as input for the VG weather generator, obtaining few missing shortwave radiation data from the Locarno-Monti station (Fig. 1).

\section{Numerical model}

In this work, we estimated the effects of changes in climate and nutrient loads on the water chemistry and phytoplankton of Lake Maggiore. To such aim, we combined the framework for the prediction of the future thermodynamics of Lake Maggiore employed in Fenocchi et al. (2018), in which only forecasts of thermal structure evolution with climate change were given, with the configuration of the General Lake Model (GLM) v2.2.0b 1D hydrodynamic model (Hipsey et al., 2014) coupled with the Aquatic EcoDynamics (AED2) ecological model (Hipsey et al., 2013) calibrated and validated over past observations of Lake Maggiore in Fenocchi et al. (2019).

The hydrodynamic model considers an enclosed-lake fixed-level configuration, which neglects actual inflows, outflow and direct rainfall to ease the application to projection studies, avoiding uncertainties in the prediction of the future hydrological regime and balance. Water elevation is kept constant through a calibrated surface input discharge which opposes evaporation and carries input loads. A fixed, fictitiously low light extinction coefficient $K_{d}=0.100 \mathrm{~m}^{-1}$ is employed in the hydrodynamic model (a fixed, field-based $K_{d}=0.227 \mathrm{~m}^{-}$ ${ }^{1}$ is nevertheless adopted in the ecological model, see Fenocchi et al., 2019) to make up for the advective heat of non-modelled riverine intrusions, by allowing deeperthan-real light penetration. Use of a fixed light extinction coefficient is legitimate as for deep lakes the thermal effects of variations in the light extinction coefficient with potential changes in the trophic status should be negligible compared to those of climate warming (Schwefel et al., 2016). The parameters of the hydrodynamic model are those calibrated in Fenocchi et al. (2017) and adjusted in Fenocchi et al. (2019).

The ecological model adopts an NPD (Nutrients Phytoplankton - Detritus) structure and directly models oxygen, phosphorus, nitrogen, silica, carbon, organic matter and phytoplankton cycles. Four phytoplankton functional groups are included: cyanophytes, diatoms, dinophytes and "c3phytes", the latter including chlorophytes, chrysophytes and cryptophytes. The effect of higher ecosystem levels is lumped into phytoplankton respiration, while that of bacteria is captured through the mineralisation of organic matter. The model parameters found for Lake Maggiore in Fenocchi et al. (2019) were employed, these being optimised for the prediction of deep-water chemistry and phytoplankton biomass and succession. Herein, methane $\left(\mathrm{CH}_{4}\right)$ oxidation and sediment fluxes for all chemical and biological compounds were included, due to the ongoing depletion of hypolimnetic $\mathrm{O}_{2}$. However, a field-based calibration of the related model parameters was not possible, as release and absorption of nutrients by bottom sediments and methane bubble outburst have never been observed in Lake Maggiore, the overlying water column having always been oxygenated. We hence relied on literature parameters, checking that negligible sediment fluxes were obtained in a preliminary simulation of the 1998-2014 
period considered in Fenocchi et al. (2019). The selected parameters (Tab. S1), determine small sediment fluxes occurring under conditions close to anoxia, as would be expected for a large deep basin as Lake Maggiore which has never experienced severe eutrophic conditions in the past and will not likely experience them in the future thanks to the control of nutrient loads (Salmaso et al., 2007). In the AED2 model and in this manuscript, compounds are expressed as concentrations and loads of their fundamental elements, i.e. $\mathrm{P}-\mathrm{PO}_{4}, \mathrm{~N}-\mathrm{NO}_{3}, \mathrm{~N}-\mathrm{NH}_{4}$, $\mathrm{Si}-\mathrm{SiO}_{2}, \quad \mathrm{C}-\mathrm{CH}_{4}$, while phytoplankton groups as concentrations of their carbon content.

\section{Performed simulations}

The presented simulations cover the 2020-2085 period. Runs start on 11 January 2016, 4 years being needed for proper spin-up of the coupled model. Complete simulations of the period were performed rather than separate runs of shorter time spans (Peeters et al., 2007; Schlabing et al., 2014; Schwefel et al., 2016). This avoids underestimating stability increase, $\mathrm{O}_{2}$ depletion and changes in phytoplankton succession, as the effects of manifold warm years are far more severe than those of sporadic ones (Straile et al., 2003, 2010; Peeters et al., 2007; Rempfer et al., 2010; Fenocchi et al., 2018).

The Swiss Climate Change Scenarios CH2011 (CH2011, 2011) were employed as climate change projections, specifically the 2025-2085 forecasts of air temperature rise for each meteorological season relative to the Southern Switzerland (CHS) region in the CH2011 Extension Series (CH2011-PLUS) No. 2 report (Fischer et al., 2015). These predictions were tailored to the reference Verbania Pallanza site in Fenocchi et al. (2018). The Swiss Climate Change Scenarios CH2018 (CH2018, 2018) were not available when this study was performed. Four scenarios were considered, taken from those included in Fenocchi et al. (2018): i) A2_upper, which depicts a harsh runaway rise of global GHG emissions; ii) A1B medium, which describes an average warming resulting from the reduction of global GHG releases from 2050; iii) RCP3PD_lower, which represents a mild heating caused by the decrease of global GHG emissions from 2020; iv) STAT_2016, which contemplates a fictitious scenario in which air temperatures are stabilised at the 2016 levels.

Two hundred runs were performed for each scenario, such sample size providing reasonably stable statistical properties, using the same random meteorological input data series employed in Fenocchi et al. (2018). This was done as meteorology shapes the thermal and chemical vertical structure of oligomictic basins as Lake Maggiore with internal mixing, especially through full turnovers and the number of years among them (Ambrosetti and Barbanti, 1999; Rogora et al., 2018). Mixing also controls primary production through the upwelling of nutrients from the hypolimnion (Morabito et al., 2012; Rogora et al., 2018). Results were statistically analysed, highlighting the uncertainties of model predictions over meteorology. Meteorological data series were created with the VectorAutoregressive Weather Generator (VG) v1.2.2 (Schlabing et al., 2014), which produced randomly perturbed datasets of air temperature, shortwave radiation, relative humidity and wind speed, given the 1998-2015 observations of these variables at Verbania Pallanza and the future changes of air temperature according to the considered scenarios. The weather generator allows including variations of other meteorological variables in addition to air temperature, which also influence lake physics, chemistry and ecology. The dependence structure among the variables is yet imposed to remain the same of the past input series (Schlabing et al., 2014).

The input loads adopted in the simulations were assembled cycling 7 times the 2006-2015 total loads inferred from the measurements at the 12 main tributaries. Such period was selected as stable nutrient loads had been approached in the Lake Maggiore catchment and major flood events did not occur (Fig. S1), so that the measured loads could also be representative of future conditions. This load series displays natural variability both at the intra- and inter-annual (Fig. S1) scales and could hence give more realistic outcomes than employing steady loads or a single repeated annual cycle. We chose not to generate random input load series as we wanted to focus on the effects of climate warming and meteorological uncertainties. Nevertheless, in addition to the four scenarios with different climate warming in which the 2006-2015 input loads were cycled, we considered for each climate scenario linear increases and decreases of the original nutrient loads reaching $\pm 30 \%$ in the last day of simulation. Such variations are the likely limit ones achievable by 2085 in the Lake Maggiore watershed. We simultaneously changed inputs of total phosphorus $\mathrm{TP}=\mathrm{PO}_{4}+\mathrm{DOP}$ and total nitrogen $\mathrm{TN}=\mathrm{NO}_{3}+\mathrm{NH}_{4}+\mathrm{DON}$, being the incoming POP and PON loads negligible for Lake Maggiore. Twelve scenarios were hence considered overall. Mean monthly input loads were obtained from the mean monthly discharges and the monthly chemical samples (Fenocchi et al., 2019). The daily concentrations input to the model were calculated dividing those loads, interpolated at the daily scale, by calibrated fictitious daily discharges which fulfil the fixed-level constraint for each run.

The initial profiles of water temperature and chemical variables were set to piecewise linear interpolations of the sampled data on the first day of simulation. For phytoplankton groups, initial constant concentrations equal to the measured integrated values were assumed in the $0-20 \mathrm{~m}$ layer, linearly decreasing to zero in the $20-30$ $\mathrm{m}$ layer with null phytoplankton below. 
To identify the top limit of the future hypoxic layer stretching from the bottom upwards, we assumed a $4 \mathrm{mg}$ $\mathrm{L}^{-1}$ threshold for hypoxia, as done for Lake Geneva (Switzerland/France) by Schwefel et al. (2016). This $\mathrm{O}_{2}$ concentration is usually assumed as limit for the protection of the biota (Paerl, 2006). In this regard, we will mention anoxia when a next to null $\mathrm{O}_{2}$ concentration appears in the simulations. To study variations in the occurrence of the phytoplankton growing season, we recorded the first and the last day of the year in which a concentration of Chlorophyll- $a(\mathrm{Chl}-a)>1.5 \mu \mathrm{g} \mathrm{L}^{-1}$ is obtained. We evaluated the possible onset of cyanophyterelated toxic hazard for recreational use (Trolle et al., 2014; Bucak et al., 2018), considering the low-risk threshold assumed by the World Health Organisation (WHO) of $10 \mu \mathrm{g} \mathrm{L}^{-1}$ for cyanophyte-related Chl- $a$ (Falconer et al., 1999) at the lake surface.

In this work, results are displayed as distributions over the 200 realisations for each scenario, representing the uncertainties of model predictions over meteorology. Water temperature and chemical variables were evaluated in the $0-20 \mathrm{~m}$ epilimnion and in the $200-370 \mathrm{~m}$ deep hypolimnion, being numerically integrated from the results at the sampling depths employed in the field observations, while phytoplankton variables were numerically integrated in the $0-20 \mathrm{~m}$ epilimnion at $1 \mathrm{~m}$ resolution. Mean annual values were considered, further averaged for each realization over the 10-year input load cycles (i.e., 2020-2025, 2026-2035, 2036-2045, 20462055, 2056-2065, 2066-2075, 2076-2085). The median annual and decadal values instead of the mean ones were considered in the calculations of the top limit of the hypoxic layer, to avoid the bias due to the variable having the bottom depth as higher bound. The initial and final days of the phytoplankton growing season were only averaged across decades, being single values for each year. For the cyanophyte-related toxic hazard, maximum surface concentrations of cyanophytes in Chl- $a$ units over the decades were considered, highlighting extreme cases. Distributions of all quantities in the first decade are variously biased as results in the 2016-2019 spin-up period were neglected.

\section{RESULTS}

\section{Water temperature}

We briefly report the water temperature dynamics under the tested scenarios (Fig. S2), the complete analysis being in Fenocchi et al. (2018).

Mean annual temperatures in the epilimnion evolve following air temperature variations. Ongoing rises are obtained for A2_upper and A1B_medium, the coincident median and mean values increasing by $+3.8^{\circ} \mathrm{C}$ for
A2 upper and $+2.7^{\circ} \mathrm{C}$ for A1B medium in the last decade relative to the first one. Temperatures initially increase for RCP3PD lower, stabilising from the 2046-2055 decade onwards, with a $+0.7^{\circ} \mathrm{C}$ increment of median and mean values in the last decade compared to the first one. Stable conditions are obtained for STAT_2016. For all scenarios, distributions symmetrically and steadily span \pm 0.3 $\pm 0.4^{\circ} \mathrm{C}$.

In the deep hypolimnion, identical ongoing increases are reproduced for A2_upper and A1B_medium, with a $+0.6-+0.7^{\circ} \mathrm{C}$ increase of median values in the last decade relative to the first one. $\mathrm{RCP} 3 \mathrm{PD}$ _lower displays a slightly milder trend, stable temperatures likely being achieved after 2085. Temperatures increase at first for STAT_2016, stabilising by the end of the simulations with a $+0.3^{\circ} \mathrm{C}$ rise of median values from the first decade. Distributions are positively skewed for A2_upper and A1B_medium, the upper whisker reaching $8.8^{\circ} \mathrm{C}$ in the last decade for A2 upper, symmetry being instead gradually achieved for RCP3PD lower and STAT 2016.

\section{Deep-hypolimnion chemistry}

In this paragraph, description of results primarily refers to constant nutrient load conditions (Fig. 2), $\pm 30 \%$ variation cases (Figs. S3-S4) being addressed when explicitly mentioned.

Asymptotical decrease of $\mathrm{O}_{2}$ is simulated for A2_upper and A1B_medium, the median values reaching anoxia by the end of the century and hypoxic concentrations being eventually obtained only for few runs. Gradual thinning of the positively skewed distributions is also reproduced. Dissolved oxygen decreases for RCP3PD_lower, median values around 1 $\mathrm{mg} \mathrm{L}^{-1}$ being reached in the second half of the century, yet an inversion of the trend is obtained in the last decade. The results for RCP3PD_lower are much more scattered and positively skewed than those for A2 upper and A1B medium, the upper whisker reaching $7.7 \mathrm{mg} \mathrm{L}^{-1}$ in the final decade, while the lower quartile lies under anoxic conditions. Median and mean concentrations are relatively stable for STAT_2016, never getting $<4 \mathrm{mg} \mathrm{L}^{-}$ ${ }^{1}$. Scattering of results is maximum for STAT_2016, the whiskers stretching in time and spanning $0-10.2 \mathrm{mg} \mathrm{L}$ 1 in the last decade, a symmetrical distribution being gradually achieved. Variations of nutrient loads cause inverse changes in $\mathrm{O}_{2}$ concentrations. For $\mathrm{A} 2$ _upper and A1B_medium, ultimately increasing nutrient loads by $+30 \%$ slightly speeds up $\mathrm{O}_{2}$ depletion, while decreasing them by $-30 \%$ does not prevent anoxia to occur in the final decade for most runs. For RCP3PD lower, variations larger than the changes in nutrient loads are simulated for the median values, being $\pm 45 \%$ in the final decade from the constant load case, whereas $\pm 17 \%$ ones result for STAT 2016. 
Median and mean values of $\mathrm{PO}_{4}$ increase for all scenarios. Increments follow an almost linear trend for

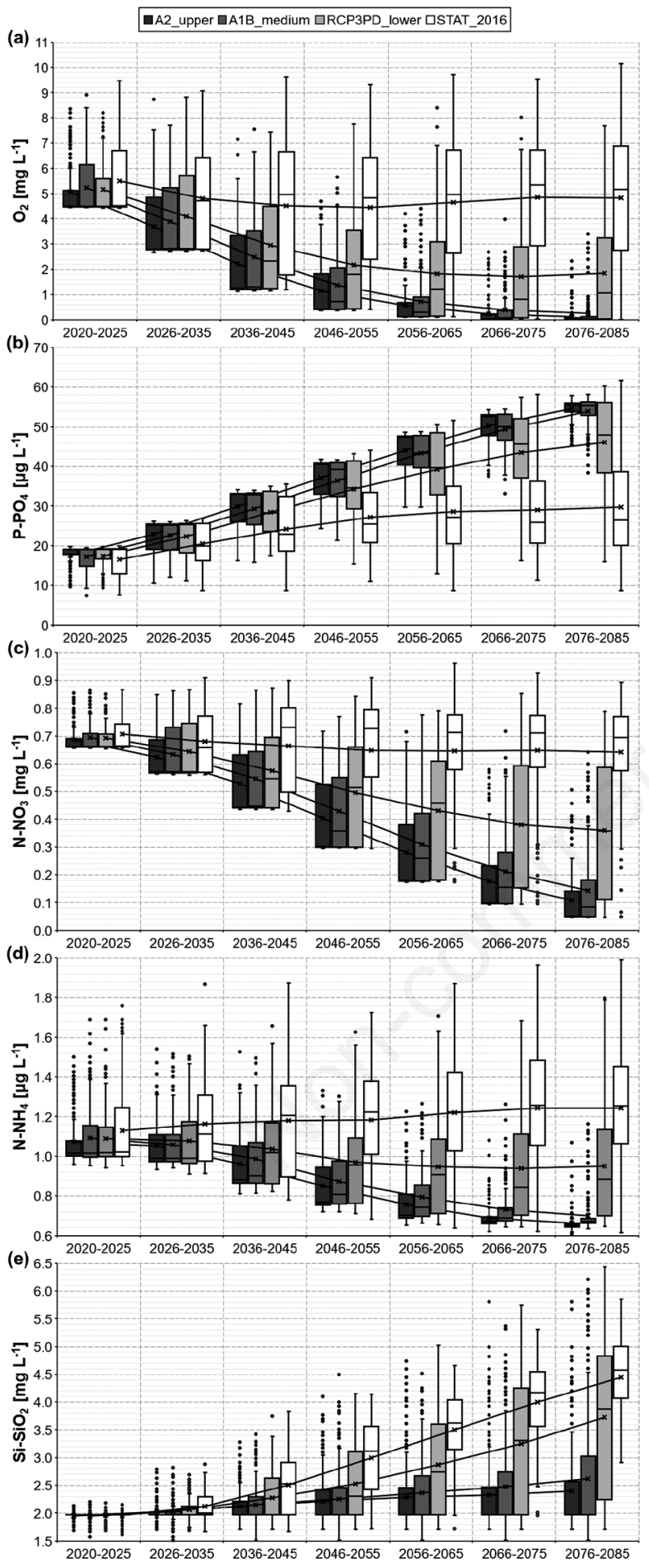

Fig. 2. Distributions over the 200 realisations of the mean annual concentrations averaged over decades of $\mathrm{O}_{2}$ (a), $\mathrm{PO}_{4}$ (b), $\mathrm{NO}_{3}$ (c), $\mathrm{NH}_{4}$ (d), $\mathrm{SiO}_{2}$ (e) in the $200-370 \mathrm{~m}$ layer for constant nutrient loads (crosses and solid lines identify the mean values and their trends).
A2 upper and A1B medium, the negatively skewed distributions gradually converging towards single values. Median values around $56 \mu \mathrm{g} \mathrm{L}^{-1}$ are simulated for $\mathrm{A} 2$ upper and $\mathrm{A} 1 \mathrm{~B}$ medium in the final decade, i.e. $\sim 3$ times those in the initial one. The rising trend steadily weakens for RCP3PD_lower and STAT_2016, stabilisation being ultimately obtained for STAT_2016 around $26 \mu \mathrm{g} \mathrm{L}^{-1}$ median value. The distributions for RCP3PD_lower and STAT_2016 are increasingly scattered, keeping negatively skewed for RCP3PD_lower and transitioning from negatively to positively skewed for STAT_2016. Variations in nutrient loads produce changes of the same sign in $\mathrm{PO}_{4}$ concentrations, the differences in the median values in the last decade from the constant load case passing from $\pm 4 \%$ for A2_upper to $\pm 15 \%$ for STAT_2016 with decreasing climate warming intensity. The final trend for STAT_2016 notably reverses under $30 \%$ load reduction because of such variation, displaying a slight yet steady decrease.

Nitrates strongly decrease and reach median values $<0.1 \mathrm{mg} \mathrm{L}^{-1}$ for A2_upper and A1B_medium, with the positively skewed distributions progressively thinning in the second half of the century. A slower reduction results for RCP3PD_lower, median and mean values stabilising in the end and the distributions gradually widening, the whiskers ranging $<0.1 \mathrm{mg} \mathrm{L}^{-1}-0.8 \mathrm{mg} \mathrm{L}^{-1}$ in the final decade. Almost steady median and mean values are last obtained for STAT 2016, the distributions being increasingly scattered and symmetrical, the whiskers spanning $0.3-0.9 \mathrm{mg} \mathrm{L}^{-1}$ in the end. Changes in nutrient loads produce variations of the same sign in $\mathrm{NO}_{3}$ concentrations, $\pm 20 \%$ variations of median values being obtained for STAT_2016 and $\pm 8 \%$ changes for the other scenarios in the last decade.

For $\mathrm{NH}_{4}$, stability of the very small concentrations around $1 \mu \mathrm{g} \mathrm{L}^{-1}$ currently obtained in Lake Maggiore is simulated for the median and mean values of all scenarios. Thinning of the positively skewed distributions is reproduced for A2_upper and A1B_medium, whereas widening for RCP3PD_lower and STAT_2016, the upper whisker eventually reaching $2 \mu \mathrm{g} \mathrm{L}^{-1}$ for STAT_2016. Increasing symmetry also results for the distributions of STAT_2016. Nutrient load variations cause changes of the same sign in $\mathrm{NH}_{4}$ concentrations, $\pm 22 \%$ alterations of median values being reproduced for STAT_2016 and $\pm 11 \%$ ones for the other scenarios in the final decade.

Invariance of the initial $2 \mathrm{mg} \mathrm{L}^{-1}$ median $\mathrm{SiO}_{2}$ concentrations results for $\mathrm{A} 2$ upper and $\mathrm{A} 1 \mathrm{~B}$ medium, while the mean values ultimately increase by $+25 \%$ as a result of the upward widening of the distributions, the outliers reaching $6 \mathrm{mg} \mathrm{L}^{-1}$ in the last decade. The median and mean values of the distributions instead increase for RCP3PD_lower and STAT_2016, values around $4.5 \mathrm{mg}$ $\mathrm{L}^{-1}$ being eventually obtained for STAT_2016. 
Distributions notably broaden for RCP3PD_lower, the upper whisker approaching $6.5 \mathrm{mg} \mathrm{L}^{-1}$ in the end. Changes in nutrient loads have opposite effects on $\mathrm{SiO}_{2}$ concentrations, being significant only for RCP3PD_lower and STAT 2016, for which $\pm 19 \%$ and $\pm 34 \%$ variations of median values are respectively obtained in the last decade. For STAT_2016, $\mathrm{SiO}_{2}$ concentrations stabilise in the end under $-30 \%$ decrease.

\section{Epilimnion chemistry}

Distributions of chemical variables in the epilimnion are less scattered than those in the deep hypolimnion and are essentially steady and symmetrical for all scenarios. General trends, represented by the almost coincident median and mean values, are hence reported.

For constant nutrient load conditions, almost stable mean annual epilimnetic concentrations (Fig. 3) are mostly reproduced under all scenarios. Only few exceptions occur: (1) $\mathrm{PO}_{4}$ increases by $+33 \%$ from the first to the last decade for $\mathrm{A} 2$ _ upper; (2) $\mathrm{NO}_{3}$ rises for A2_upper and A1B_medium from the 2046-2055 decade onwards, with $+\overline{7} 6 \%$ and $+55 \%$ respective final increments; (3) $\mathrm{SiO}_{2}$ increases for all scenarios, the increments in the final decade ranging $+107 \%-+428 \%$ from STAT_2016 to A2_upper with increasing climate warming intensity. Nutrient load variations ultimately reaching $\pm 30 \%$ affect the mean annual concentrations of the four scenarios (Figs. S5-S6) as follows: i) negligible alterations of $\mathrm{O}_{2}$ concentrations of the same sign of nutrient load changes are reproduced, modifications in the last decade being within $\pm 2 \%$ from the constant load case; ii) $\pm 12 \%- \pm 16 \%$ final variations of the same sign are obtained for $\mathrm{PO}_{4}$ concentrations; iii) variations of the same sign result for concentrations of $\mathrm{NO}_{3}$ and $\mathrm{NH}_{4}$, which ultimately reach $\pm 30 \%- \pm 35 \%$ for $\mathrm{NO}_{3}$ and $\pm 18 \%$ $- \pm 22 \%$ for $\mathrm{NH}_{4}$; iv) inverse alterations occur for $\mathrm{SiO}_{2}$ concentrations, being around $\pm 28 \%- \pm 50 \%$ in the last decade from A2_upper to STAT_2016 with decreasing climate warming intensity.

\section{Phytoplankton biomass and succession}

As for chemical variables, the distributions of mean annual phytoplankton concentrations in the epilimnion are weakly scattered and generally steady and symmetrical, so that the trends of the almost identical median and mean values are described. Results for constant nutrient loads (Fig. 4) are presented first, effects of $\pm 30 \%$ variations (Figs. S7-S8) being reported later.

Considering total Chl $a, \mathrm{a}+5 \%$ asymptotical increase from the first to the last decade results for STAT_2016, steady concentrations for RCP3PD_lower and an ongoing decrease for A2_upper and A1B_medium, reaching - 14\% and $-11 \%$ respectively. Narrowing of the distributions is observed for A2_upper and A1B medium. Cyanophytes remain constant for RCP3PD_lower and STAT_2016. A

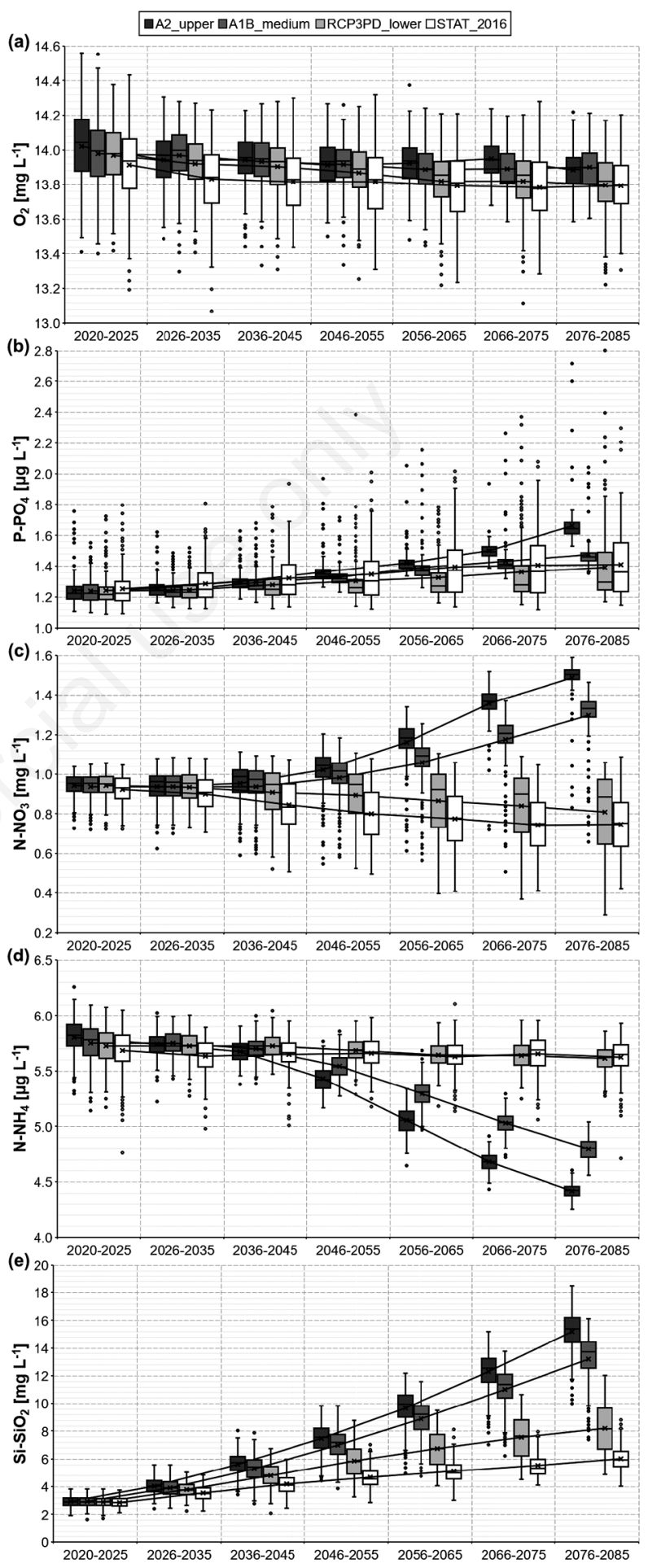

Fig. 3. Distributions over the 200 realisations of the mean annual concentrations averaged over decades of $\mathrm{O}_{2}$ (a), $\mathrm{PO}_{4}$ (b), $\mathrm{NO}_{3}$ (c), $\mathrm{NH}_{4}(\mathrm{~d}), \mathrm{SiO}_{2}$ (e) in the $0-20 \mathrm{~m}$ layer for constant nutrient loads (crosses and solid lines identify the mean values and their trends). 
rise by 3.9 and 3.1 times the cyanophyte concentrations in the first decade is obtained in the last one for A2_upper

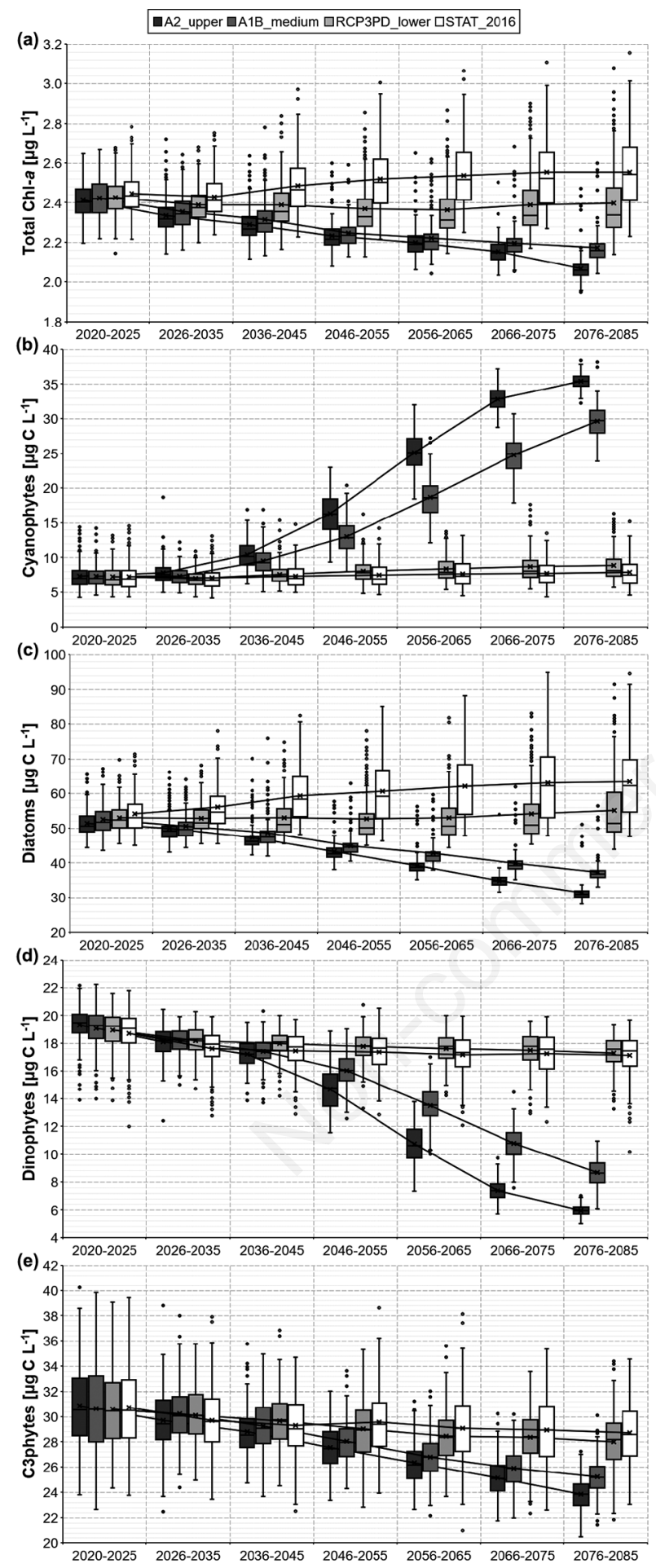

Fig. 4. Distributions over the 200 realisations of the mean annual concentrations averaged over decades of total Chl- $a$ (a), cyanophytes (b), diatoms (c), dinophytes (d), c3phytes (e) in the 0-20 m layer for constant nutrient loads (crosses and solid lines identify the mean values and their trends). and $\mathrm{A} 1 \mathrm{~B}$ medium respectively, the increase eventually damping for A2 upper. Diatoms ultimately decrease by around $-35 \%$ for $\mathrm{A} 2$ upper and $\mathrm{A} 1 \mathrm{~B}$ medium, the trend being steeper for A2 upper. Steady values and a $+17 \%$ final increase are respectively obtained for RCP3PD_lower and STAT_2016. A new equilibrium is also ultimately approached in STAT 2016. Distributions of mean annual diatom concentrations contract for A2 upper and A1B medium and expand towards the upper side for RCP3PD_lower and STAT_2016. Dinophytes more than halve from the 2046-2055 decade onwards for A2_upper and A1B_medium, more markedly for A2 upper, showing only a minor decrease for RCP3PD_lower and STAT_2016. Finally, c3phytes decrease by $-20 \%$ for A2_upper and A1B_medium, being limited to $-8 \%$ for RCP3PD lower and STAT 2016.

Variations in nutrient loads reaching $\pm 30 \%$ alter the mean annual concentrations of the four scenarios as follows: i) changes of the same sign around $\pm 21 \%- \pm 23 \%$ from the constant load case result for total Chl- $a$ in the last decade; ii) cyanophytes and diatoms are more affected by changes in nutrient loads than total phytoplankton, with $\pm 32 \%- \pm 39 \%$ final variations for cyanophytes and $\pm 29 \%- \pm 33 \%$ for diatoms; iii) dinophytes show alterations of $\pm 18 \%- \pm 24 \%$ in the final decade; iv) c3phytes are weakly affected, with $\pm 5 \%- \pm 8 \%$ ultimate variations. The trends of mean annual concentrations of total phytoplankton and of individual functional groups with changes in nutrient loads resemble linear combinations of the trends for constant loads under the different scenarios and the nutrient load variations, without significant alterations in the distributions. There are two exceptions yet for A2_upper: i) for total phytoplankton, in the $+30 \%$ case concentrations decrease in the last decade, despite the previous slightly rising trends; ii) for cyanophytes, in the $-30 \%$ case equilibrium is achieved in the last decade, whereas for $+30 \%$ there is still an ongoing increase.

\section{Top limit of the bottom hypoxic layer}

Bottom hypoxia is simulated to occur with different intensities under all considered combinations of climate change scenarios and nutrient load conditions (Fig. 5).

Hypoxia rapidly develops for A2_upper and A1B_medium regardless of nutrient loads, the top limit of the hypoxic layer stabilising from the 2046-2055 decade at $\sim 80 \mathrm{~m}$ depth. The distributions of results contract completely, with only few outliers.

For RCP3PD_lower, hypoxia increases more slowly in the first half of the century. The median top limit never reaches the $\sim 80 \mathrm{~m}$ depth value of $\mathrm{A} 2$ upper and A1B_medium and the distributions do not converge towards such threshold, being only bounded by it. Changes in nutrient loads do not cause significant 
variations to the median values, yet they noticeably influence the distributions. In the first half of the century, contraction reduces in the $-30 \%$ case and sharpens for $+30 \%$. In the second half of the century: i) for $+30 \%$, the distributions of the top limit of the hypoxic layer stabilise at $\sim 100 \mathrm{~m}$ depth median value and bottom hypoxia occurs under all realisations; ii) for constant loads, a slight recovery of median values eventually occurs and bottom hypoxia disappears in runs with more intense mixing; iii) for $-30 \%$, the recovery of median values is clearer and the whole interquartile range does not have a hypoxic bottom in the final decade.

The median values of the distributions for STAT_2016 show hypoxia only in the 2026-2035 decade, the top limit of the layer being at $\sim 280 \mathrm{~m}$ depth under all nutrient load conditions. Hypoxia subsequently endures in the upper half of the distributions. While identical steady distributions are obtained for $+30 \%$ and constant nutrient loads, contraction occurs for $-30 \%$, bottom anoxia being present in the last decade only for a few outliers.

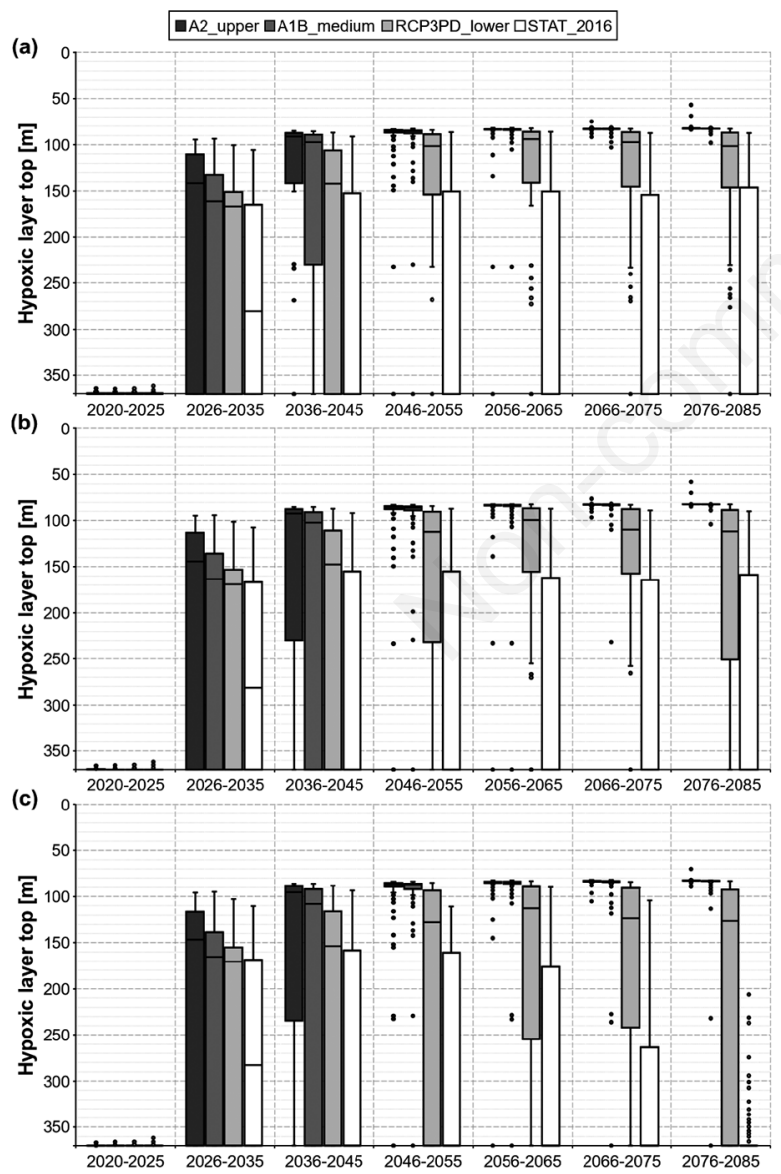

Fig. 5. Distributions over the 200 realisations of the decadal medians of the median annual top limits of the bottom hypoxic layer for $+30 \%$ linear increase of nutrient loads (a), constant nutrient loads (b), $-30 \%$ linear decrease of nutrient loads (c).

\section{Phytoplankton growing season}

The distributions of the beginning and of the end of the phytoplankton growing season are virtually symmetrical. Trends are hence described considering the almost coincident median and mean values. Results for constant nutrient loads (Fig. 6) are illustrated first, effects of $\pm 30 \%$ changes (Figs. S9-S10) being analysed later.

The beginning and the end of the phytoplankton growing season are postponed from the 2046-2055 decade onwards for A2_upper and A1B_medium, the delay reaching $+2-+3$ weeks in the final decade. The distributions contract for A2_upper and A1B_medium, their amplitude reducing in the last decade to 2 weeks for the beginning and $2-3$ weeks for the end. For RCP3PD_lower and STAT_2016, the beginning and the end of the growing season do not shift and almost coincide between the two scenarios, respectively occurring in the third decade of January and in the first decade of November. The distributions steadily span 1 month for the beginning and $1-1.5$ months for the end.

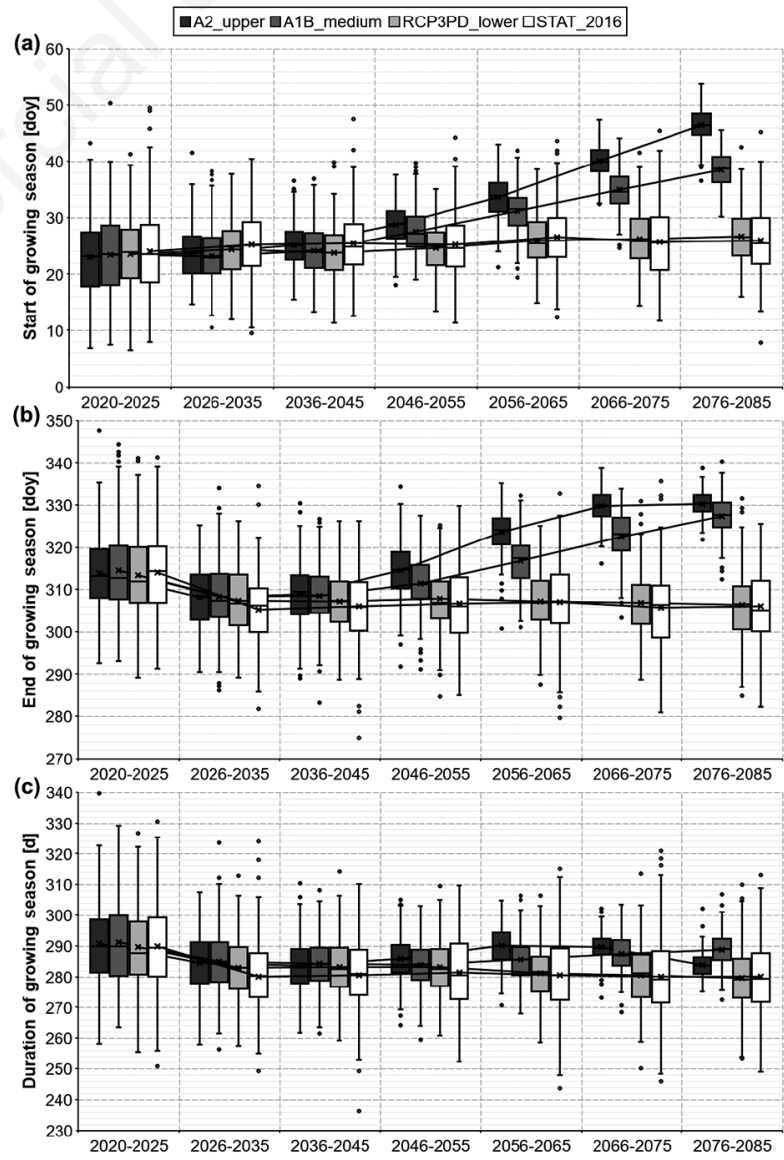

Fig. 6. Distributions over the 200 realisations of the mean decadal beginning (a), end (b) and duration (c) of phytoplankton growing season for constant nutrient loads (crosses and solid lines identify the mean values and their trends). 
Neglecting the first incomplete decade, the duration of the phytoplankton growing season thus remains almost constant for all scenarios at $280-290$ days. Stable distributions with an amplitude of $1.5-2$ months are obtained for RCP3PD_lower and STAT_2016, reducing to $2-3$ weeks for A2_upper and A1B_medium.

The beginning of the growing season occurs earlier and later for nutrient load increase and decrease, respectively. The opposite results for the end, which happens earlier for decreasing loads and later for increasing ones. For nutrient load increase, the variations in the final decade from the constant load case are -9 - 4 days for the beginning and $+10-+28$ days for the end. Such ranges are spanned with increasing absolute values from A2_upper to STAT_2016 with decreasing climate warming intensity. Higher variations result for nutrient load decrease, respectively being $+7-+14$ days for the beginning and $-66--30$ days for the end, ranges still being spanned with increasing absolute values from A2_upper to STAT_2016. The amplitude of distributions is not affected by changes in nutrient loads.

\section{Cyanophyte-related toxic hazard}

Lake Maggiore is not expected to suffer from cyanophyte-related toxic hazard in the $21^{\text {st }}$ century considering the $10 \mu \mathrm{g} \mathrm{L}^{-1}$ low-risk threshold concentration of cyanophyte-related Chl- $a$ assumed by the WHO (Falconer et al., 1999) at the surface (Fig. 7). Such limit is never exceeded by the distributions under the considered nutrient load conditions, except for a single outlier for constant loads and five of them for $+30 \%$ increase under the A2_upper scenario. The margin to the threshold yet reduces with the cyanophyte surge simulated for A2_upper and A1B_medium, with relevant differences among nutrient load conditions. Considering the worst scenario A2 upper, the margin of the median and mean values of the distributions reduces from $614 \%\left(1.4 \mu \mathrm{g} \mathrm{L} \mathrm{L}^{-1}\right.$ concentration) in the first decade to, in the last decade: $41 \%$ for $+30 \%$ ( $7.1 \mu \mathrm{g} \mathrm{L}^{-1}$ concentration), $75 \%$ for constant nutrient loads (5.7 $\mu \mathrm{g} \mathrm{L}^{-1}$ concentration), $122 \%$ for $-30 \%$ (4.5 $\mu \mathrm{g} \mathrm{L}^{-1}$ concentration). Stable risk is simulated for RCP3PD_lower and STAT_2016 under both constant input and $-30 \%$ cases. A significant increase results instead for $+30 \%$, the margin of the median and mean values reducing in the last decade to $+245 \%$ ( $2.9 \mu \mathrm{g} \mathrm{L}^{-1}$ concentration) for both RCP3PD_lower and STAT_2016.

\section{DISCUSSION}

\section{Hypolimnetic hypoxia and anoxia}

The hypolimnion of Lake Maggiore would most likely reach hypoxic to anoxic conditions in the second half of the $21^{\text {st }}$ century, regardless of reductions in both global GHG emissions and external loads. This would hamper the habitat of many living species, especially those living at large depths (Matzinger et al., 2007). However, while for A2 upper and A1B_medium the decline towards anoxia is unavoidable but for few outliers, for RCP3PD lower chances exist that if intense mixing events occurred the lake would never become hypoxic. Nevertheless, if average to reduced mixing was met under RCP3PD_lower, the deep hypolimnion would become hypoxic to anoxic and the recovery from such conditions would be initially slow, as happens in $>75 \%$ of the realisations. According to model predictions, the decrease of hypolimnetic $\mathrm{O}_{2}$ could be fully halted and recovered by the end of the $21^{\text {st }}$ century under average mixing conditions only through an unrealistically early and abrupt stabilisation of air temperatures at the present levels, as per the STAT_2016 scenario. Still, anoxia could arise under STAT_2016 if exceptionally low mixing occurred.

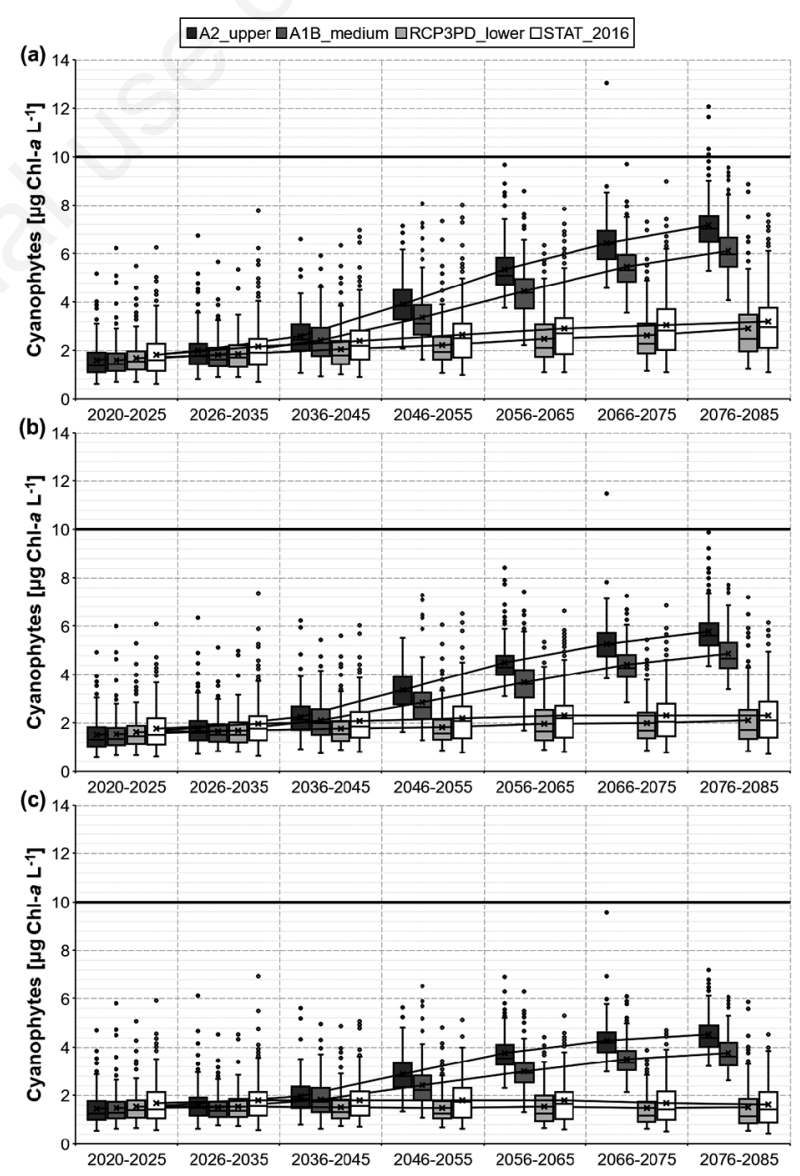

Fig. 7. Distributions over the 200 realisations of the decadal maxima of cyanophyte-related Chl- $a$ at the surface for $+30 \%$ linear increase of nutrient loads (a), constant nutrient loads (b), $-30 \%$ linear decrease of nutrient loads (c) (the thick horizontal line identifies the low-risk threshold concentration of $10 \mu \mathrm{g} \mathrm{L}^{-1}$ for cyanophyte-related Chl- $a$ assumed by the WHO (Falconer et al., 1999), crosses and solid lines identify the mean values and their trends). 
The decrease in the frequency of complete mixing due to the rising vertical temperature gradient between the epilimnion and the hypolimnion (Livingstone, 2003) would then largely overwhelm local management of nutrient loads from the catchment and would barely be opposed by global control of GHG emissions. In Fenocchi et al. (2018), we found that hypolimnion isolation would be further strengthened by the following side effects of climate warming: i) reduction of wind speed; ii) decrease in the duration of complete-mixing events; iii) drop of mixing depth in the years without full turnover; iv) protraction and enhancement of stratification. The importance of a sustainable reduction of global GHG emissions, as per the RCP3PD_lower scenario, is nevertheless clear from the simulations. Such cut would allow avoiding complete anoxia apart under significantly worse mixing conditions than the average ones and reverting the decreasing trend under the average ones, which would likely lead to good oxygenation in the $22^{\text {nd }}$ century if the predicted trend continued.

The results obtained herein for Lake Maggiore agree with those of Matzinger et al. (2007) for Lake Ohrid (North Macedonia/Albania) and of Sahoo et al. (2013) for Lake Tahoe (USA), who found from continuous numerical simulations of the $21^{\text {st }}$ century for these deep oligomictic and oligotrophic basins under non-sustainable climate warming an eventual halt of full turnovers and the arise of bottom anoxia. In those studies, simulated severe reductions in nutrient loads could only slightly influence the speed of $\mathrm{O}_{2}$ depletion.

Hypolimnetic hypoxia to anoxia have already been reached in the second half of the $20^{\text {th }}$ century in the most eutrophied deep subalpine lakes, Lake Lugano (Switzerland/Italy) and Lake Iseo (Italy), leading to the establishment of a chemical stratification gradient which hinders mixing (Barbieri and Mosello, 1992; Garibaldi et al., 1999). The predictions of hypolimnetic $\mathrm{O}_{2}$ concentration in the $21^{\text {st }}$ century given here for Lake Maggiore would likely qualitatively hold for the other two deep subalpine lakes, Lake Garda and Lake Como (Italy), due to the similar climatic, morphometric, chemical and trophic characteristics (Salmaso et al., 2007, 2014; Rogora et al., 2018). Under such conditions, future full turnovers would lead to surface hypoxia due to the mixing of the oxic epilimnion with the hypoxic to anoxic hypolimnion, with harmful effects on the biota. This has already happened in Lake Lugano after the 2006 full turnover, which occurred after $\sim 40$ years of meromixis, causing extensive fish deaths (Holzner et al., 2009).

\section{Chemical dynamics}

The accumulation of $\mathrm{PO}_{4}$ in the deep hypolimnion mirrors $\mathrm{O}_{2}$ depletion, being set to arise under all tested scenarios with different intensity. The phenomenon could be fully avoided only if more intense mixing than the average occurred under RCP3PD_lower and STAT_2016. Accumulation of $\mathrm{PO}_{4}$ is yet more moderate than $\mathrm{O}_{2}$ consumption, also due to the decrease in the mineralisation rate of DOP and POP caused by falling $\mathrm{O}_{2}$ concentrations. Variations in input $\mathrm{PO}_{4}$ affect the accumulation process less than linearly because of hypolimnion isolation and the mediation of primary production. Future full turnovers would resuspend confined $\mathrm{PO}_{4}$, causing strong algal blooms, potentially of harmful cyanophytes (Rempfer $e t$ al., 2010; Rogora et al., 2018).

The strong decrease in hypolimnetic $\mathrm{NO}_{3}$ for A2_upper and A1B_medium and the milder one for RCP3PD_lower are tied to the decrease of hypolimnetic $\mathrm{O}_{2}$, which bounds nitrification. Ammonium would then be expected to increase in the deep hypolimnion, yet the simulated concentrations continue to be negligible as the present ones. The reason behind this is twofold: (1) production of $\mathrm{NH}_{4}$ reduces as the mineralisation rate of PON and DON depends on $\mathrm{O}_{2}$ concentration; (2) the swift nitrification currently observed in Lake Maggiore due to the very low reducing properties of its waters, modelled by the very high nitrification rate and very low denitrification rate calibrated in Fenocchi et al. (2019), is supposed to endure in the future within the simulations, due to the fixed model parameters. The less than linear changes in deep-water $\mathrm{NO}_{3}$ and $\mathrm{NH}_{4}$ for variations in input loads of the same nutrients are still due to hypolimnion isolation and primary production.

The increase in hypolimnetic $\mathrm{SiO}_{2}$ obtained for all scenarios is mostly linked to long-term model drift, due to both imperfect calibration and simplified $\mathrm{SiO}_{2}$ cycle within AED2 (Hipsey et al., 2013). Drift is minimised for A2 upper and A1B_medium due to the increasing stability, steady concentrations resulting for the realisations without full turnovers. For A2_upper and A1B_medium, the rise of $\mathrm{SiO}_{2}$ in the deep hypolimnion would also occur due to the simulated decline of $\mathrm{SiO}_{2}$ uptaking diatoms and c3phytes, the latter group including chrysophytes.

Despite the ecological model not having been explicitly calibrated for epilimnetic chemistry, only $\mathrm{SiO}_{2}$ appreciably suffers from positive drift in such layer, even if the higher increase obtained for A2 upper and A1B_medium than for RCP3PD_lower and STAT_2016 should be rightfully due to the reproduced decline of diatoms and c3phytes. Yankova et al. (2017) found that in Lake Zurich (Switzerland) the epilimnetic $\mathrm{SiO}_{2}$ concentration has already been increasing due to the decline of diatoms at the expense of cyanophytes, triggered by increasing surface water temperature and stability. The increase of epilimnetic $\mathrm{PO}_{4}$ under $\mathrm{A} 2$ _upper is due to the surge of cyanophytes at the expense of diatoms, the formers having a smaller maximum $\mathrm{P}$ 
biomass and a lower $\mathrm{P}$ uptake rate than the latters (Fenocchi et al., 2019). Variations in nutrient loads cause inverse changes in the epilimnetic concentrations of $\mathrm{SiO}_{2}$, as they directly determine the population of diatoms and c3phytes.

\section{Phytoplankton dynamics}

Under the A2 upper and A1B_medium scenarios, the reduced availability of $\mathrm{PO}_{4}$ following decreasing mixing and the shrunken habitat for diatoms and dinophytes due to their low temperature optimum (Fenocchi et al., 2019) slightly prevail over the boosted cyanophyte activity, causing the small decrease of overall phytoplankton. These phenomena are almost balanced for RCP3PD_lower, in which negligible variations in the mean annual concentrations of both total Chl- $a$ and individual functional groups are observed. The small increase of overall phytoplankton and diatoms obtained for STAT 2016 may be ascribed to the rising nutrient availability following increasing mixing.

The small variations of overall phytoplankton biomass under constant nutrient loads for all scenarios are due to $\mathrm{P}$ limitation keeping its central role under a warmer climate. The nutrient-determined carrying capacity of the lake remains in fact identical. Matzinger et al. (2007) also found that for Lake Ohrid primary production would continue to depend on P load with future climate change, enhanced phytoplankton growth and $\mathrm{P}$ recycling with warmer temperature almost exactly compensating diminished $\mathrm{P}$ availability in the euphotic zone due to reduced mixing. Similar results were found by Schlabing et al. (2014) with simulations of deep oligotrophic Lake Constance (Germany/Switzerland/Austria).The major simulated change to phytoplankton in Lake Maggiore with the water warming and increase of stability reproduced for A2_upper and A1B_medium is the redistribution of the algal biomass among functional groups and within the growing season. Cyanophytes would extraordinarily rise due to their high temperature optimum (Fenocchi et al., 2019), respectively quadrupling and triplicating their mean annual concentrations for A2_upper and A1B_medium at the expense of diatoms and dinophytes, which prefer low temperatures (Fenocchi et al., 2019). Diatoms would hence lose their dominance in Lake Maggiore, being equalled in mean annual concentration by cyanophytes within 2085 . However, the final damping of the rising trend of cyanophytes simulated for A2_upper under constant nutrient loads, equilibrium being reached for $-30 \%$ loads and undisturbed rise continuing for $+30 \%$, shows that they cannot increase indefinitely, as beyond certain temperatures nutrient limitation replaces temperature limitation. In the $+30 \%$ case, the decline of diatoms and dinophytes due to high surface temperatures outdoes in the last decade the rise of cyanophytes, causing total phytoplankton to decrease despite increasing nutrient loads. The maximum annual diatom concentration is reproduced to remain constant for A2_upper and A1B_medium as their late winter bloom at exceptionally low water temperature observed in Lake Maggiore (Fenocchi et al., 2019) would still occur in the future, yet their concentration later within the year would decrease as they would lose their niche against cyanophytes. For c3phytes, the general decrease obtained even under STAT_2016 should be ascribed to model drift due to the difficulties in calibrating such assemblage of three phytoplankton classes, even if the stronger reduction obtained for A2_upper and A1B_medium is realistically linked to their niche being taken by cyanophytes.

The enduring relevance of $\mathrm{P}$ limitation on phytoplankton biomass confirms the relevant role of watershed load management under severe climate warming. Cyanophytes are affected by variations in nutrient loads, so that local management efforts can effectively limit them, even if the major boost due to water temperature rise can be successfully and promptly opposed only by a sustainable reduction of global GHG emissions as per the RCP3PD_lower scenario, without the delay and damping simulated for hypolimnetic temperature and chemistry. We also proved that the rise of cyanophytes with climate warming would reach a limit beyond which temperature limitation would stop governing such phenomenon, being replaced by nutrient limitation. Specifically, under $-30 \%$ nutrient load reduction the rise of cyanophytes would be halted by 2085 under A2_upper.

\section{Derived parameters}

Variations in nutrient loads do not affect the final top limit of the bottom hypoxic layer for A2 upper and A1B medium, whose distributions converge towards $\sim 80$ $\mathrm{m}$ depth, i.e. the boundary between the metalimnion and hypolimnion of Lake Maggiore. The whole hypolimnion would hence most probably become hypoxic to anoxic by the mid- $21^{\text {st }}$ century under A2_upper and A1B_medium, regardless of nutrient load reduction. Sustainably addressing global GHG emissions as per the RCP3PD_lower scenario would effectively limit hypolimnetic oxygen depletion. Under such conditions, complete hypolimnion isolation would be avoided and the synergy with nutrient load reduction would result in good bottom oxygenation being present in the end in $>25 \%$ of the simulations. On the contrary, an increase of nutrient loads would invalidate the benefits of global-scale interventions.

The delayed beginning of the growing season for A2_upper and A1B medium despite air temperature warming should be ascribed to the decrease in nutrient availability at the end of winter due to reduced mixing, so that more time is needed for Chl- $a$ concentrations $>1.5 \mu \mathrm{g}$ 
$\mathrm{L}^{-1}$ to build up due to slower diatom growth. This contradicts the assumption that climate warming leads to earlier phytoplankton blooms (Elliott et al., 2005; Peeters et al., 2007; Schlabing et al., 2014). The delayed end of the growing season for A2_upper and A1B_medium is due to the higher temperatures deferring phytoplankton death. The duration of the phytoplankton growing season nonetheless remains constant for all scenarios under constant loads likely as a certain nutrient supply can support phytoplankton growth for a specific amount of time. In fact, positive and negative variations in nutrient loads respectively increase and decrease the duration of the growing season, inversely shifting the occurrence of its beginning and end. They also affect more the end of the growing season than its beginning as the former is mainly nutrient-dependent, while the latter is primarily temperature-dependent. The decrease of nutrient loads produces higher variations than the increase, as in the latter case temperature limitation bounds the extension of the growing season allowed by the additional nutrients.

Regarding cyanophyte-related toxic hazard, even if the low-risk threshold of $10 \mu \mathrm{g} \mathrm{L}^{-1}$ for cyanophyte-related Chl$a$ assumed by the WHO (Falconer et al., 1999) at the surface is only exceeded in few runs for A2 upper even under $+30 \%$ nutrient load increase, it should be highlighted that simulations represent the average concentration over the lake surface. This threshold concentration has been already exceeded in recent years during hot summers with low winds in shallow bays of Lake Maggiore, even if surface-averaged concentrations were well below the limit (Callieri et al., 2014; Stefani et al., 2016; Morabito et al., 2018). Therefore, we suggest interpreting the results regarding cyanophyte-related toxic hazard as follows: "under an $x$-fold increase of the maximum surfaceaveraged summer cyanophyte concentration relative to the present one, there could be a correspondent $x$-fold increase of the hazard that the low-risk threshold is locally exceeded in sheltered areas compared to the current one". In this regard, a reduction of nutrient loads from the catchment would allow limiting toxic hazard even under A2 upper and A1B medium. Control of external loads would therefore remain essential for the protection of water quality even under critical climate change. In case global warming is properly addressed as per the RCP3PD_lower scenario, no increase of cyanophyte-related toxic hazard would be expected for Lake Maggiore, and possibly for other oligotrophic lakes in temperate areas.

\section{Limits and validity of model predictions}

In addition to the calibration problems of coupled hydrodynamic-ecological models due to the huge parameter space, the herein presented results are affected by the assumed invariance of chemical and biological dynamics through fixed parameterisation. Shifts in phytoplankton and bacterial species and adaptation of the present ones through microevolution cannot in fact be simulated. In Lake Maggiore, changes in phytoplankton species have been triggered by climatic factors since the 2000s, when stable oligotrophic conditions were restored (Morabito et al., 2012). Modifications in zooplankton and fish species, higher ecosystem levels having been lumped for model conciseness, can also influence phytoplankton through top-down control, as was observed in the past on Lake Maggiore (Manca and Ruggiu, 1998).

Even if the model was calibrated to make up for hypolimnetic oxygenation by the intrusion of inflows through adjusted oxygen consumption parameters of organic matter mineralisation, variations in hypolimnetic oxygenation with climate warming cannot be properly considered and would lead the model to diverge from reality. This could occur with changes to the hydrological regime following variations in rainfalls (CH2011, 2011; $\mathrm{CH} 2018$, 2018). The same holds for the direct supply of nutrients to the hypolimnion through the underflow of tributaries, which was reproduced in the model through adjusted sinking of particulate organic matter. Variations in the intra-annual distribution of inflows to Lake Maggiore would also modify the timing of nutrient delivery, thus affecting the entire ecosystem (Anderson, 2000; Morabito et al., 2012; Trolle et al., 2014). We did not address such changes, which bound the validity of the present predictions, as we only tested variations in overall annual nutrient loads. Not having explicitly simulated rainfalls, especially summer short events of high intensity, is also an issue, the related impulse loads primarily from diffuse sources having been found to stimulate in Lake Maggiore blooms of cyanophytes (Callieri et al., 2014; Morabito et al. 2018) and chlorophytes (Tapolczai et al., 2015; Morabito et al., 2018).

Despite these problems, the present forecasts allow additional insight on the effects of future climate changes on the chemistry and phytoplankton of Lake Maggiore to the extrapolation of observed trends. The model showed limited drift and instabilities, which were mostly identified thanks to the comparison against the STAT_2016 scenario with constant nutrient loads. We also highlighted meteorological uncertainties through the multiple realisations performed for each scenario and the relative statistical analysis. Our results also agree with other model simulations of future climate change on comparable deep oligomictic and oligotrophic basins (Matzinger et al., 2007; Sahoo et al., 2013) and confirm evaluations made through observed trends on Lake Maggiore (Stefani et al., 2016; Rogora et al., 2018). Therefore, while the quantitative evaluations should be critically viewed, being hindered by model limitations and future uncertainties (Özkundakci et al., 2011; Fenocchi et al., 2018, 2019), the herein provided qualitative results 
report definite indications on the future effectiveness of reduction measures of global GHG emissions and of local control of nutrient loads from the watershed for Lake Maggiore. These evaluations would variously hold also for the other deep subalpine lakes and for other deep oligomictic basins in temperate areas.

\section{CONCLUSIONS}

The simulations presented in this study show that the hypolimnion of Lake Maggiore would most likely become enduringly anoxic due to lack of mixing by the end of the century if global GHG emissions were not sustainably addressed. Lasting hypolimnetic hypoxia would still be highly probable even under a prompt decrease of GHG emissions, due to the already compromised present situation and to the recovery inertia of deep waters. The dynamics of chemical variables in the hypolimnion will be in fact primarily driven by the increase of stability dictated by global warming. In case of complete hypolimnion isolation occurring under inadequate climate politics, management of catchment loads would have limited effects. On the other hand, under sustainable control of GHG emissions nutrient load reduction would accelerate the recovery of hypolimnetic hypoxia, while an increase would spoil it.

Measures to reduce external loads would promptly impact phytoplankton biomass, nutrient limitation occurring also under climate warming. While the rise of cyanophytes relative to the other groups could be avoided only halting surface water warming through the global decrease of GHG emissions, their peak summer concentration could be limited controlling nutrient loads even under severe water warming, reducing the risk of cyanophyte-related toxic hazard. While oligotrophic Lake Maggiore would likely not suffer from general cyanotoxin emergency even under maximum climate change, local risk in sheltered bays would be significantly enhanced.

Lake Maggiore and other deep oligomictic lakes in temperate areas would then need a timely synergy between the reduction of global GHG emissions and the control of nutrient loads to avoid persistent alteration of water quality and ecosystem and promptly recover from damage which has already occurred. Global interventions on GHG emissions to limit climate change are central, as the consequent increase of stability and surface water warming can largely outdo the benefits of measures to reduce external loads.

\section{ACKNOWLEDGMENTS}

The CH2011 and CH2011-PLUS data were obtained from the Center for Climate Systems Modeling (C2SM).
The employed limnological and meteorological data were collected through the research programs funded by the International Commission for the Protection of ItalianSwiss Waters (CIPAIS) for Lake Maggiore. We thank the technical and scientific staff of CNR-IRSA in Verbania Pallanza involved in field work and data analysis and management through the years. Data for the Verbania Pallanza weather station from 2009 onwards were provided by the Regional Environmental Protection Agency of Piedmont (ARPA Piemonte). Data for the Locarno-Monti weather station were supplied by MeteoSwiss. Discharges for River Maggia and River Verzasca were obtained from the Swiss Federal Office for the Environment (UFAM). Limnological research on Lake Maggiore is performed within the framework of the LTER (Long-Term Ecological Research) Italian and European networks (site "Southern Alpine Lakes", LTER_EU_IT_008).

We dedicate this paper to the late Giuseppe Morabito of CNR-IRSA, who encouraged our research and provided high-quality phytoplankton data for Lake Maggiore.

\section{REFERENCES}

Adrian R, O'Reilly CM, Zagarese H, Baines SB, Hessen DO, Keller W, Livingstone DM, Sommaruga R, Straile D, Van Donk E, Weyhenmeyer GA, Winder M, 2009. Lakes as sentinels of climate change. Limnol. Oceanogr. 54:22832297.

Ambrosetti W, Barbanti L, 1999. Deep water warming in lakes: an indicator of climatic change. J. Limnol. 58:1-9.

Anderson NJ, 2000. Miniview: diatoms, temperature and climatic change. Eur. J. Phycol. 35:307-314.

Barbieri A, Mosello R, 1992. Chemistry and trophic evolution of Lake Lugano in relation to nutrient budget. Aquat. Sci. 54:219-237.

Bruce LC, Hamilton D, Imberger J, Gal G, Gophen M, Zohary $\mathrm{T}$, Hambright KD, 2006. A numerical simulation of the role of zooplankton in $\mathrm{C}, \mathrm{N}$ and $\mathrm{P}$ cycling in Lake Kinneret, Israel. Ecol. Model. 193:412-436.

Bucak T, Trolle D, Tavşanoğlu ÜN, Çakıroğlu Aİ, Özen A, Jeppesen E, Beklioğlu M, 2018. Modeling the effects of climatic and land use changes on phytoplankton and water quality of the largest Turkish freshwater lake: Lake Beyşehir. Sci. Total Environ. 621:802-816.

Burger DF, Hamilton DP, Pilditch CA, 2008. Modelling the relative importance of internal and external nutrient loads on water column nutrient concentrations and phytoplankton biomass in a shallow polymictic lake. Ecol. Model. 211:411423.

Callieri C, Bertoni R, Contesini M, Bertoni F, 2014. Lake level fluctuations boost toxic cyanobacterial "oligotrophic blooms". PLoS ONE 9:e109526.

Carpenter SR, Caraco NF, Correll DL, Howarth RW, Sharpley AN, Smith VH, 1998. Nonpoint pollution of surface waters with phosphorus and nitrogen. Ecol. Appl. 8:559-568. 
Carpenter SR, Stanley EH, Vander Zanden MJ, 2011. State of the world's freshwater ecosystems: physical, chemical, and biological changes. Annu. Rev. Env. Resour. 36:75-99.

CH2011, 2011. Swiss climate change scenarios CH2011. C2SM, MeteoSwiss, ETH, NCCR Climate, and OcCC, Zurich, Switzerland: $88 \mathrm{pp}$.

CH2018, 2018. CH2018 - Climate scenarios for Switzerland: technical report. National Centre for Climate Services, Zurich, Switzerland: $271 \mathrm{pp}$.

Cui Y, Zhu G, Li H, Luo L, Cheng X, Jin Y, Trolle D, 2016. Modeling the response of phytoplankton to reduced external nutrient load in a subtropical Chinese reservoir using DYRESM-CAEDYM. Lake Reserv. Manage. 32:146-157.

Elliott JA, Thackeray SJ, Huntingford C, Jones RG, 2005. Combining a regional climate model with a phytoplankton community model to predict future changes in phytoplankton in lakes. Freshwater Biol. 50:1404-1411.

Falconer I, Bartram J, Chorus I, Kuiper-Goodman T, Utkilen H, Burch M, Codd GA, 1999. Safe levels and safe practices, $p$. 161-182. In: I. Chorus and J. Bartram (eds.), Toxic cyanobacteria in water: a guide to their public health consequences, monitoring and management. E \& FN Spon.

Fenocchi A, Rogora M, Morabito G, Marchetto A, Sibilla S, Dresti C, 2019. Applicability of a one-dimensional coupled hydrodynamic-ecological numerical model to future projections in a very deep large lake (Lake Maggiore, Northern Italy/Southern Switzerland). Ecol. Model. 392:38-51.

Fenocchi A, Rogora M, Sibilla S, Ciampittiello M, Dresti C, 2018. Forecasting the evolution in the mixing regime of a deep subalpine lake under climate change scenarios through numerical modelling (Lake Maggiore, Northern Italy/Southern Switzerland). Clim. Dynam. 51:3521-3536.

Fenocchi A, Rogora M, Sibilla S, Dresti C, 2017. Relevance of inflows on the thermodynamic structure and on the modeling of a deep subalpine lake (Lake Maggiore, Northern Italy/Southern Switzerland). Limnologica 63:42-56.

Fenocchi A, Sibilla S, 2016. Hydrodynamic modelling and characterisation of a shallow fluvial lake: a study on the Superior Lake of Mantua. J. Limnol. 75:455-471.

Fischer AM, Liniger MA, Appenzeller C, 2015. Climate scenarios of seasonal means: extensions in time and space. CH2011 Extension Series No. 2, Zurich, Switzerland: 18 pp.

Gal G, Hipsey MR, Parparov A, Wagner U, Makler V, Zohary $\mathrm{T}, 2009$. Implementation of ecological modeling as an effective management and investigation tool: Lake Kinneret as a case study. Ecol. Model. 220:1697-1718.

Gal G, Makler-Pick V, Shachar N, 2014. Dealing with uncertainty in ecosystem model scenarios: application of the single-model ensemble approach. Environ. Modell. Softw. 61:360-370.

Garibaldi L, Mezzanotte V, Brizzio MC, Rogora M, Mosello R, 1999. The trophic evolution of Lake Iseo as related to its holomixis. J. Limnol. 58:10-19.

Hamilton DP, Schladow SG, 1997. Prediction of water quality in lakes and reservoirs. Part I - model description. Ecol. Model. 96:91-110.

Hipsey MR, Bruce LC, Hamilton DP, 2013. Aquatic EcoDynamics (AED) model library: science manual. AED Report. The University of Western Australia, Perth, Australia: 34 pp.
Hipsey MR, Bruce LC, Hamilton DP, 2014. GLM - General Lake Model: model overview and user information. AED Report \#26. The University of Western Australia, Perth, Australia: $42 \mathrm{pp}$.

Holzner CP, Aeschbach-Hertig W, Simona M, Veronesi M, Imboden DM, Kipfer R, 2009. Exceptional mixing events in meromictic Lake Lugano (Switzerland/Italy), studied using environmental tracers. Limnol. Oceanogr. 54:1113-1124.

Jankowski T, Livingstone DM, Bührer $H$, Forster $R$, Niederhauser P, 2006. Consequences of the 2003 European heat wave for lake temperature profiles, thermal stability, and hypolimnetic oxygen depletion: implications for a warmer world. Limnol. Oceanogr. 51:815-819.

Jeppesen E, Søndergaard M, Jensen JP, et al., 2005. Lake responses to reduced nutrient loading - an analysis of contemporary long-term data from 35 case studies. Freshwater Biol. 50:1747-1771.

Jöhnk KD, Huisman J, Sharples J, Sommeijer B, Visser PM, Stroom JM, 2008. Summer heatwaves promote blooms of harmful cyanobacteria. Glob. Change Biol. 14:495-512.

Kara EL, Hanson P, Hamilton D, et al., 2012. Time-scale dependence in numerical simulations: assessment of physical, chemical, and biological predictions in a stratified lake at temporal scales of hours to months. Environ. Modell. Softw. 35:104-121.

Livingstone DM, 2003. Impact of secular climate change on the thermal structure of a large temperate Central European lake. Climatic Change 57:205-225.

Manca M, Ruggiu D, 1998. Consequences of pelagic food-web changes during a long-term lake oligotrophication process. Limnol. Oceanogr. 43:1368-1373.

Marcé R, Moreno-Ostos E, García-Barcina JM, Armengol J, 2010. Tailoring dam structures to water quality predictions in new reservoir projects: assisting decision-making using numerical modeling. J. Environ. Manage. 91:1255-1267.

Matzinger A, Schmid M, Veljanoska-Sarafiloska E, Patceva S, Guseska D, Wagner B, Müller B, Sturm M, Wüest A, 2007. Eutrophication of ancient Lake Ohrid: global warming amplifies detrimental effects of increased nutrient inputs. Limnol. Oceanogr. 52:338-353.

Mieleitner J, Reichert P, 2006. Analysis of the transferability of a biogeochemical lake model to lakes of different trophic state. Ecol. Model. 194:49-61.

Morabito G, Oggioni A, Austoni M, 2012. Resource ratio and human impact: how diatom assemblages in Lake Maggiore responded to oligotrophication and climatic variability. Hydrobiologia 698:47-60.

Morabito G, Rogora M, Austoni M, Ciampittiello M, 2018. Could the extreme meteorological events in Lake Maggiore watershed determine a climate-driven eutrophication process? Hydrobiologia 824:163-175.

Moss B, Kosten S, Meerhoff M, Battarbee RW, Jeppesen E, Mazzeo N, Havens K, Lacerot G, Liu Z, De Meester L, Paerl H, Scheffer M, 2011. Allied attack: climate change and eutrophication. Inland Waters 1:101-105.

Özkundakci D, Hamilton DP, Trolle D, 2011. Modelling the response of a highly eutrophic lake to reductions in external and internal nutrient loading. New Zeal. J. Mar. Fresh. 45:165-185.

Paerl HW, 2006. Assessing and managing nutrient-enhanced 
eutrophication in estuarine and coastal waters: interactive effects of human and climatic perturbations. Ecol. Eng. 26:40-54.

Peeters F, Straile D, Lorke A, Livingstone DM, 2007. Earlier onset of the spring phytoplankton bloom in lakes of the temperate zone in a warmer climate. Glob. Change Biol. 13:1898-1909.

Pinardi M, Fenocchi A, Giardino C, Sibilla S, Bartoli M, Bresciani M, 2015. Assessing potential algal blooms in a shallow fluvial lake by combining hydrodynamic modelling and remote-sensed images. Water 7:1921-1942.

Posch T, Köster O, Salcher MM, Pernthaler J, 2012. Harmful filamentous cyanobacteria favoured by reduced water turnover with lake warming. Nat. Clim. Change 2:809-813.

Read JS, Winslow LA, Hansen GJA, Van Den Hoek J, Hanson PC, Bruce LC, Markfort CD, 2014. Simulating 2368 temperate lakes reveals weak coherence in stratification phenology. Ecol. Model. 291:142-150.

Rempfer J, Livingstone DM, Blodau C, Forster R, Niederhauser P, Kipfer R, 2010. The effect of the exceptionally mild European winter of 2006-2007 on temperature and oxygen profiles in lakes in Switzerland: a foretaste of the future? Limnol. Oceanogr. 55:2170-2180.

Reynolds CS, 2006. The Ecology of Phytoplankton. Cambridge University Press, New York, USA: 552 pp.

Rogora M, Buzzi F, Dresti C, Leoni B, Lepori F, Mosello R, Patelli M, Salmaso N, 2018. Climatic effects on vertical mixing and deep-water oxygen content in the subalpine lakes in Italy. Hydrobiologia 824:33-50.

Sahoo GB, Schladow SG, Reuter JE, Coats R, Dettinger M, Riverson J, Wolfe B, Costa-Cabral M, 2013. The response of Lake Tahoe to climate change. Climatic Change 116:71-95.

Salmaso N, Buzzi F, Cerasino L, Garibaldi L, Leoni B, Morabito G, Rogora M, Simona M, 2014. Influence of atmospheric modes of variability on the limnological characteristics of large lakes south of the Alps: a new emerging paradigm. Hydrobiologia 731:31-48.

Salmaso N, Morabito G, Garibaldi L, Mosello R, 2007. Trophic development of the deep lakes south of the Alps: a comparative analysis. Fund. Appl. Limnol. 170:177-196.

Scheffer M, Straile D, van Nes EH, Hosper H, 2001. Climatic warming causes regime shifts in lake food webs. Limnol. Oceanogr. 46:1780-1783.

Schlabing D, Frassl MA, Eder MM, Rinke K, Bárdossy A, 2014. Use of a weather generator for simulating climate change effects on ecosystems: a case study on Lake Constance. Environ. Modell. Softw. 61:326-338.

Schladow SG, Hamilton DP, 1997. Prediction of water quality in lakes and reservoirs: part II - Model calibration, sensitivity analysis and application. Ecol. Model. 96:111-123.

Schwefel R, Gaudard A, Wüest A, Bouffard D, 2016. Effects of climate change on deepwater oxygen and winter mixing in a deep lake (Lake Geneva): comparing observational findings and modeling. Water Resour. Res. 52:8811-8826. Snortheim CA, Hanson PC, McMahon KD, Read JS, Carey CC, Dugan HA, 2017. Meteorological drivers of hypolimnetic anoxia in a eutrophic, north temperate lake. Ecol. Model. 343:39-53.

Stefani F, Salerno F, Copetti D, Rabuffetti D, Guidetti L, Torri G, Naggi A, Iacomini M, Morabito G, Guzzella L, 2016. Endogenous origin of foams in lakes: a long-term analysis for Lake Maggiore (northern Italy). Hydrobiologia 767:249265.

Straile D, Jöhnk K, Rossknecht H, 2003. Complex effects of winter warming on the physicochemical characteristics of a deep lake. Limnol. Oceanogr. 48:1432-1438.

Straile D, Kerimoglu O, Peeters F, Jochimsen MC, Kümmerlin R, Rinke K, Rothhaupt K-O, 2010. Effects of a half a millennium winter on a deep lake - a shape of things to come? Glob. Change Biol. 16:2844-2856.

Tapolczai K, Anneville O, Padisák J, Salmaso N, Morabito G, Zohary T, Tadonléké RD, Rimet F, 2015. Occurrence and mass development of Mougeotia spp. (Zygnemataceae) in large, deep lakes. Hydrobiologia 745:17-29.

Trolle D, Elliott JA, Mooij WM, Janse JH, Bolding K, Hamilton DP, Jeppesen E, 2014. Advancing projections of phytoplankton responses to climate change through ensemble modelling. Environ. Modell. Softw. 61:371-379.

Trolle D, Hamilton DP, Pilditch CA, Duggan IC, Jeppesen E, 2011. Predicting the effects of climate change on trophic status of three morphologically varying lakes: implications for lake restoration and management. Environ. Modell. Softw. 26:354-370.

Trolle D, Jørgensen TB, Jeppesen E, 2008a. Predicting the effects of reduced external nitrogen loading on the nitrogen dynamics and ecological state of deep Lake Ravn, Denmark, using the DYRESM-CAEDYM model. Limnologica 38:220-232.

Trolle D, Nielsen A, Rolighed J, Thodsen H, Andersen HE, Karlsson IB, Refsgaard JC, Olesen, JE, Bolding K, Kronvang B, Søndergaard M, Jeppesen E, 2015. Projecting the future ecological state of lakes in Denmark in a 6 degree warming scenario. Clim. Res. 64:55-72.

Trolle D, Skovgaard H, Jeppesen E, 2008b. The Water Framework Directive: setting the phosphorus loading target for a deep lake in Denmark using the 1D lake ecosystem model DYRESM-CAEDYM. Ecol. Model. 219:138-152.

Visser PM, Ibelings BW, Bormans M, Huisman J, 2016. Artificial mixing to control cyanobacterial blooms: a review. Aquat. Ecol. 50:423-441.

Winder M, 2012. Lake warming mimics fertilization. Nat. Clim. Change 2:771-772.

Yankova Y, Neuenschwander S, Köster O, Posch T, 2017. Abrupt stop of deep water turnover with lake warming: drastic consequences for algal primary producers. Sci. Rep.UK 7:13770. 